\title{
Indicating street vitality in excavated towns. Spatial configurative analyses applied to Pompeii
}

\begin{abstract}
The aim of this contribution is to show how it is possible to indicate degrees of street life and economic attractiveness in excavated towns through micro- and macro-spatial configurative analyses. The space syntax method is able to calculate the spatial configuration of built environments and compare it with numerical socio-economic data (Hillier, this volume). It is capable of identifying the spatial features for vital shopping areas, various social classes' spatial preferences when choosing a dwelling area, and the spatial features of the location of various institutional buildings in a contemporary urban context.

At present, research on the urban environment by means of space syntax theory and methods tends to focus on macro-scale spatial conditions. However, the micro-scale aspects should not be neglected. For this purpose, spatial methods were developed and tested out with regard to the topological relationship between private and public space. Issues such as various degrees of inter-visibility between windows and doors, density of entrances, topological depth between private and public space, and degree of constitutedness were taken into account. It became clear that micro-spatial measurements depend on the macro-spatial ones (van Nes and Lopez 20Io). Together they offer knowledge about the spatial conditions for different issues, such as vital street life, urban safety, social interactions and their interdependence. Everything seems to depend on various degrees of adjacency, permeability and intervisibility being taken into account on different levels of scale.

When applying these spatial analysis tools on excavated sites, empirical socio-economic knowledge from a modern urban context is required. Then it is possible to derive from the spatial analysis information on street life, poverty and various degrees of social control on excavated sites. Pompeii is one of the best preserved towns from the Roman period and it is used as an example to derive interpretations by means of spatial analysis.
\end{abstract}

\section{Introduction}

The Roman town of Pompeii was suddenly buried by an unexpected eruption of the volcano Vesuvius on 24th August 79 AD. About 20,000 inhabitants were living there at that time. The town was buried under a 6-metre layer of volcanic ash, which preserved forever evidence of urban life at that moment almost two thousand years ago. Two thirds of the town are now excavated. Due to its strict orthogonal street grid, it is easy to reconstruct the street structure of the un-excavated parts. A lot has been investigated and written about Pompeii. However, even though there is a wealth of published material, the linkage between various disciplines as well as the linkage between artefacts and their location has not yet been sufficiently established.

From a perspective outside archaeology, urban researchers in the field of space syntax are concerned with the space-society relationship (Hillier, this volume). The focus lies on how activities in society shape the spatial outcome and how this spatial outcome in turn affects human behaviour. The product of this organisational set-up can only be under- 
stood from written documents, plans, and, naturally, the spatial organisation of the built environment itself. Conversely, gaining knowledge of human behaviour in built environments requires that human activities in urban space are recorded. An understanding of the relationship between society and its physical product necessitates at least some tools which focus on spatial issues and a consideration of the underlying laws of urban space itself.

From an urban designer's perspective, results from research on built environments are useful to some extent because they enable us to predict future socio-economic consequences of our design proposals. Therefore the space syntax method can give indications of possible effects of spatial changes. Similarly, results from space syntax research in a modern urban context are to some extent useful to archaeologists for understanding past societies by means of spatial analysis. In particular the relationship among the flow of human movement, economic activities and the degree of spatial integration can indicate various degrees of street vitality in excavated towns. Understanding this relationship depends on an accurate reconstruction of the street network of past built environments.

As it is possible to reconstruct Pompeii's entire street network, the Roman town proves an interesting case study for examining social and economic street life in ancient times using spatial analysis. Since many items found in buildings are well preserved, it is possible to identify from an archaeological point of view what kind of function various spaces had in the past. This contribution will focus on how the dispersal of urban functions relates to the spatial configurative analysis of Pompeii's street network. More specifically, the results collated from spatial analysis will be correlated with the location of various building functions as they have been identified by archaeologists.

\section{Definition of urban space}

The success of space syntax seems to be due to at least two factors: a concise definition of space and a high degree of falsifiability and testability. When testing statements or hypotheses, we must be able to determine whether they are true or false. Therefore the concepts used in research have to be well defined for providing reliable scientific explanations and an understanding of how built environments function. The clearly defined spatial notions of the space syntax method have contributed to operational and uniform research methods, which again have contributed to solid, empirically based theories and generalisations on the relationship between society and space.

Hillier distinguishes between intrinsic and extrinsic properties of space. Extrinsic ones determine how spatial units relate to one another. The configurative laws of space are based on a space's degree of accessibility, permeability, and visibility in relationship to all spaces (Hillier, this volume). When one intends to understand settlements in terms of these laws, they are regarded as sets of spaces. Here primarily topological issues become relevant. Volumes, textures and size are not taken into consideration. When regarded in purely extrinsic 
terms, spaces are shape-free. It is only their inter-relational aspect or structure that counts here. Each space has one or more functions, either for occupation or movement. Therefore, extrinsic properties of space concern built form and their containing functions (Marcus 2000, p. 40).

A systematic account of the extrinsic properties of built environments seen as sets of spaces allows the identification of genotypes of different settlements. In this respect merely generative processes count. What is important here is to describe the hidden spatial structure of built environments.

While extrinsic properties of space concern invisible, structural relationships, intrinsic properties refer to visible ones. They rely on things we can see, such as the shape, size, and texture, of physical objects (like for example buildings) placed in space (Hillier I999, p. I). They consist mostly of geometrical properties and are responsible for the different phenotype each settlement has. Describing the intrinsic spatial properties of a built environment is not an abstraction of the meaning and intentions of the physical objects. First and foremost, a physical object's purpose is important at the time it was made. In later contexts it is mostly left out of consideration. In this respect, intrinsic properties of space account for the interrelationship between built form and meaning (Marcus 2000, p. 40). In research traditions based on urban morphology and place phenomenology concepts of space form part of intrinsic properties of space, viz. they consist of descriptions of building typologies, shape of built volumes, windows, doors, forms of squares etc.

In archaeological research on Pompeii, the phenotype of various artefacts has been extensively recorded. Some examples are the temple of Fortuna Augusta, Capitolium, Temple of Apollo, and the well-preserved villas such as the House of Sallust and the House of the Black Anchor (Zanker I998). However, the genotype of the various buildings and the city have hardly been taken into account. There has been some space syntax research on buildings and street network over the last I5 years (Laurence I996; Poehler 2006; Kaiser 2000; Fridell Anter and Weilguni 2003; DeLaine 2004; Newsome 2009). However the linkage between Pompeii's private and public space is not made at all in the analysis of extrinsic properties of space or the genotypes of various streets.

\section{The space syntax method applied to excavated towns}

When applying space syntax to excavated sites, it is important to clarify the chronological context of the analysis. Often, changes to the street network and buildings through time are layered upon each other (Stöger 2009). Some layers might be lost while others are highly visible. There are several maps of Pompeii's street network. Furthermore, Hans Eschebach and Liselotte Eschebach (Eschebach I993) recorded every excavated building and carefully plotted their walls and openings on maps. Because of the artefacts found in Pompeii, various functions have been attributed to excavated buildings. 
It is easy to identify bakeries, public baths, temples, taverns, wool workshops, smithies, inns, drinking places, and brothels. The presence of shops, however, is difficult to ascertain, since artefacts found inside buildings could be used for private use as well as for sale. In contrast to this approach, Ray Laurence used the length of the streets in metres and divided it by the number of doorways (Laurence I996, p. 89). In his view this analysis suggests a large number of comings and goings in such streets, which is a condition for micro-scale economic activities.

\section{The macro-scale tools}

Figure I shows how global integration is calculated for a small settlement. As the analyses show, the main street is the most spatially integrated street in terms of the smallest number of direction changes to all other streets. The back street is the most spatially segregated street. Every time people change direction from one street to another, they take a topological step. A person has to change direction many times to reach all other streets from the back street. Hence, the back street is topologically deep, whereas the main street is topologically shallow.

A small settlement can be calculated easily by hand. However, when analysing larger settlements, with more than a hundred thousand street segments, the relationship of a street to all other streets in the network can be calculated using specialised software. Since the space syntax method analyses pure spatial relationships quantitatively, the results can be correlated with numerical statistical data such as pedestrian flow rates, property prices, crime dispersal etc (Hillier, this volume). Hence, the degree of a street network's spatial integration gives an indication of the extent of street life and the location of economic activities.

In excavated towns, spatial analysis results can only be correlated with the location of the various urban functions which have been indicated by the artefacts discovered in buildings. Functions such as public baths, bakeries, taverns, religious buildings and dwellings are easy to identify. The location of shops, however, is difficult to confirm, because artefacts found in the rooms adjacent to the public street can be used privately as well as being offered for sale.

The global and local integration analyses of Pompeii's street network indicate the location of the most important streets. Figure 2 shows a global integration analysis with the location pattern of shops. It suggests how accessible each street is in relation to all the others. The black colour shows the most integrated streets, while the light grey represents the most segregated ones. As research has shown in present-day cities, the most integrated streets have the highest flows of pedestrians. Shops are also located in the most integrated streets (Hillier et al. I998; van Nes 2005). In Pompeii, the two main streets, Via Stabiana and Via di Nola, have the highest integration values, followed by the Via dell'Abbondanza. 
A simple settlement

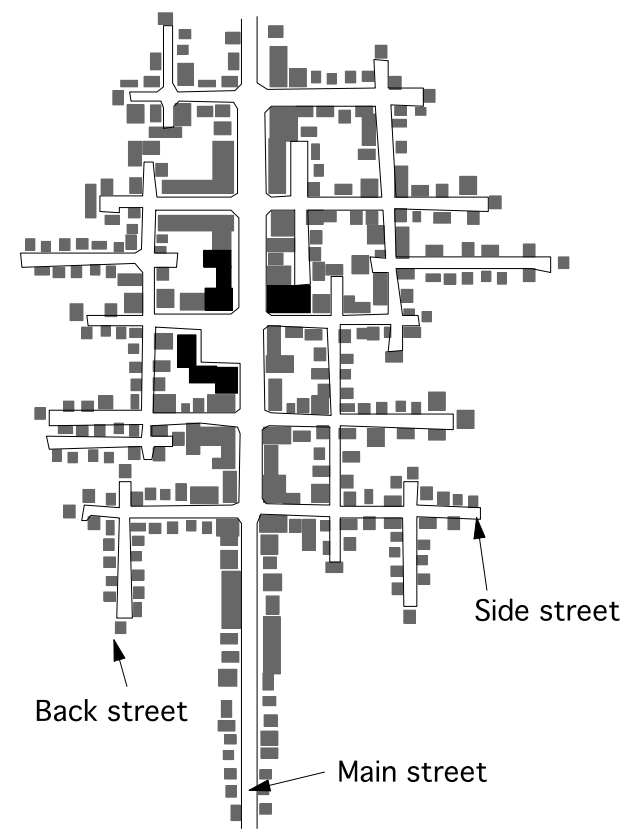

Justified graph showing the connection between the different streets

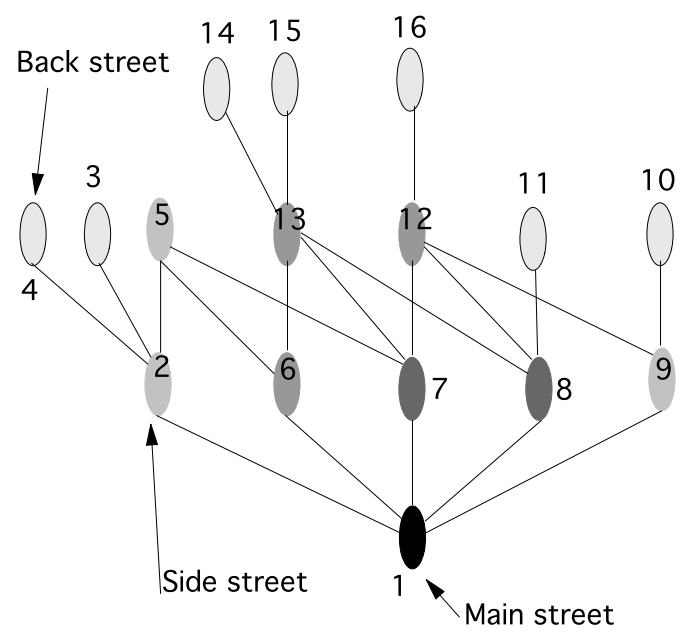

An axial map of the settlement's street net

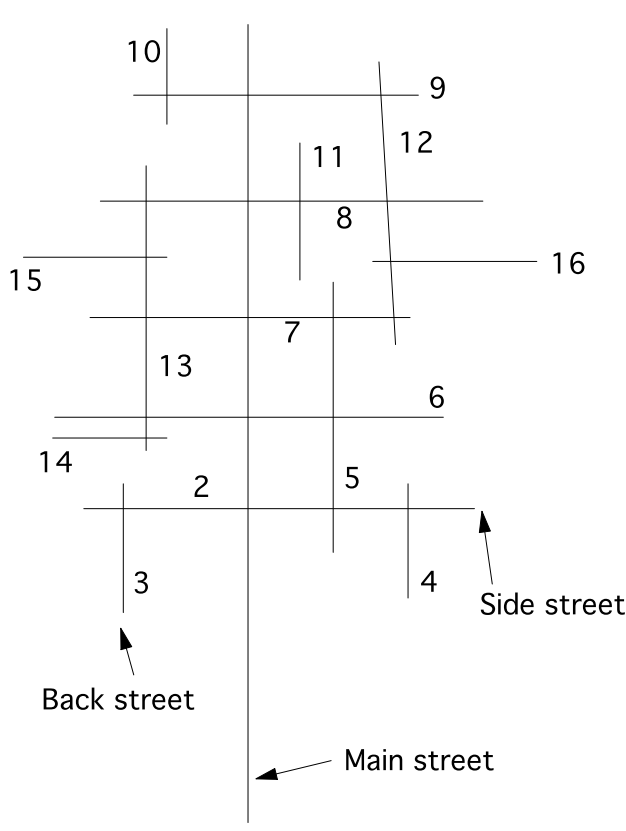

Axial Integration analysis

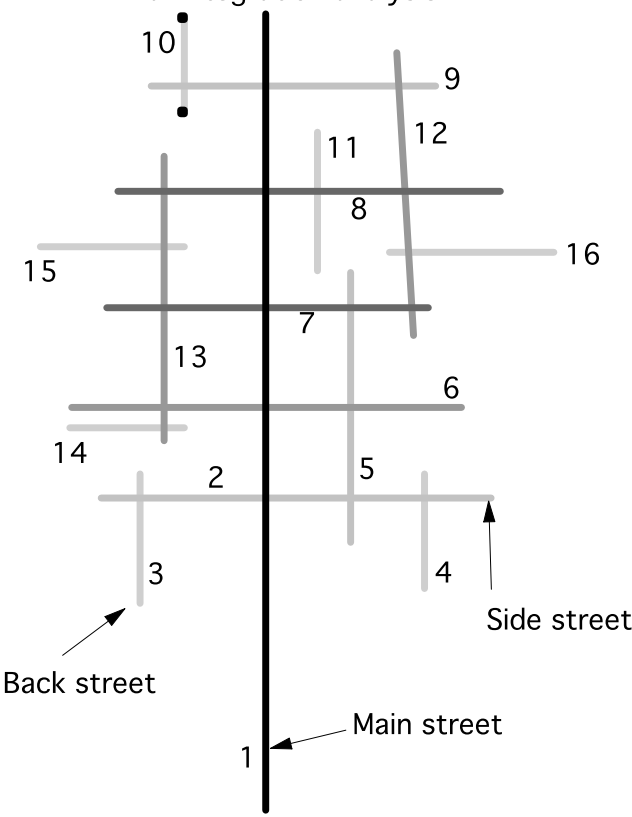

Figure 1 | Space syntax analyses of a simple settlement. 
In the local integration analysis, local angular analysis, and isovists analysis, the same integration structure can be seen as in the global integration analysis.

The two highly spatially integrated main streets are planned according to the ideal of Roman city planning, where they are called decumanus and cardus. Pompeii's oldest urban areas have an organic street network. At the time of the eruption, it was slightly adjusted to the ideal Roman town plan with its strictly orthogonal street pattern.

A two-step analysis shows how much of an area can be reached when changing directions twice from a particular street. When this approach is applied to the two most integrated streets in Pompeii, it shows that all other streets can be reached within two direction changes. Moreover, the density of side streets is very high along the integrated main streets. As was already mentioned, shops are located in the most topologically and metrically central streets in Pompeii, just as they do at present in most cities (van Nes 2005). The black pattern of shops (as indicated by the Eschebachs) corresponds with the integration values of the macro-scale analyses.

A recently developed Space Syntax measure, angular analysis, takes as its basis the angular relationship between streets. Most main routes through and between urban areas consist of long streets ending up at another long street with an angle close to r8o degrees. As expected, the decumanus and cardus are highlighted more in the angular analyses than in the global integration analyses. The correlation between the location pattern of shops and the occurrence of graffiti on the walls tend to be in streets with a high local angular integration value. It can be presumed that these streets were more frequented than others.

In his book, Roman Pompeii: Space and Society, Laurence identified the location of the centres of various local neighbourhoods on the basis of the location of public water fountains and provision of high-quality drinking water (water fountains). He argues that these fountains would have been used by people living in close proximity to them, and they probably functioned as a natural contact point between neighbours (Laurence I996, p. 98). These water fountains were nearly always located at a street junction. If the water quality is equally distributed around the town, it can be presumed that the locals chose the water fountain in closest proximity to their residence. These locations can be subjected to topological analyses to relate the shortest metrical radiuses to the integration values discussed above. What we find is that the water fountains were located in places with high local integration values and associated with short metrical distances.

Figure 3 shows the location of the various local centres for different neighbourhoods (or vici) derived from the spatial topological analyses with a metrical radius of 80 metres. It is not unreasonable to assume that there would be two or three more local centres in the unexcavated areas north of Via dell'Abbondanza. In these unexcavated areas, the structure of the presumed streets has both high integration values and a high density of streets within a short metric distance. In addition, it needs to be pointed out that these unexcavated streets, in terms of point depth and line analyses (as well as axial and segment analyses), suggest that in the unexcavated area in the eastern part of Pompeii lies an important (strong) local centre. 


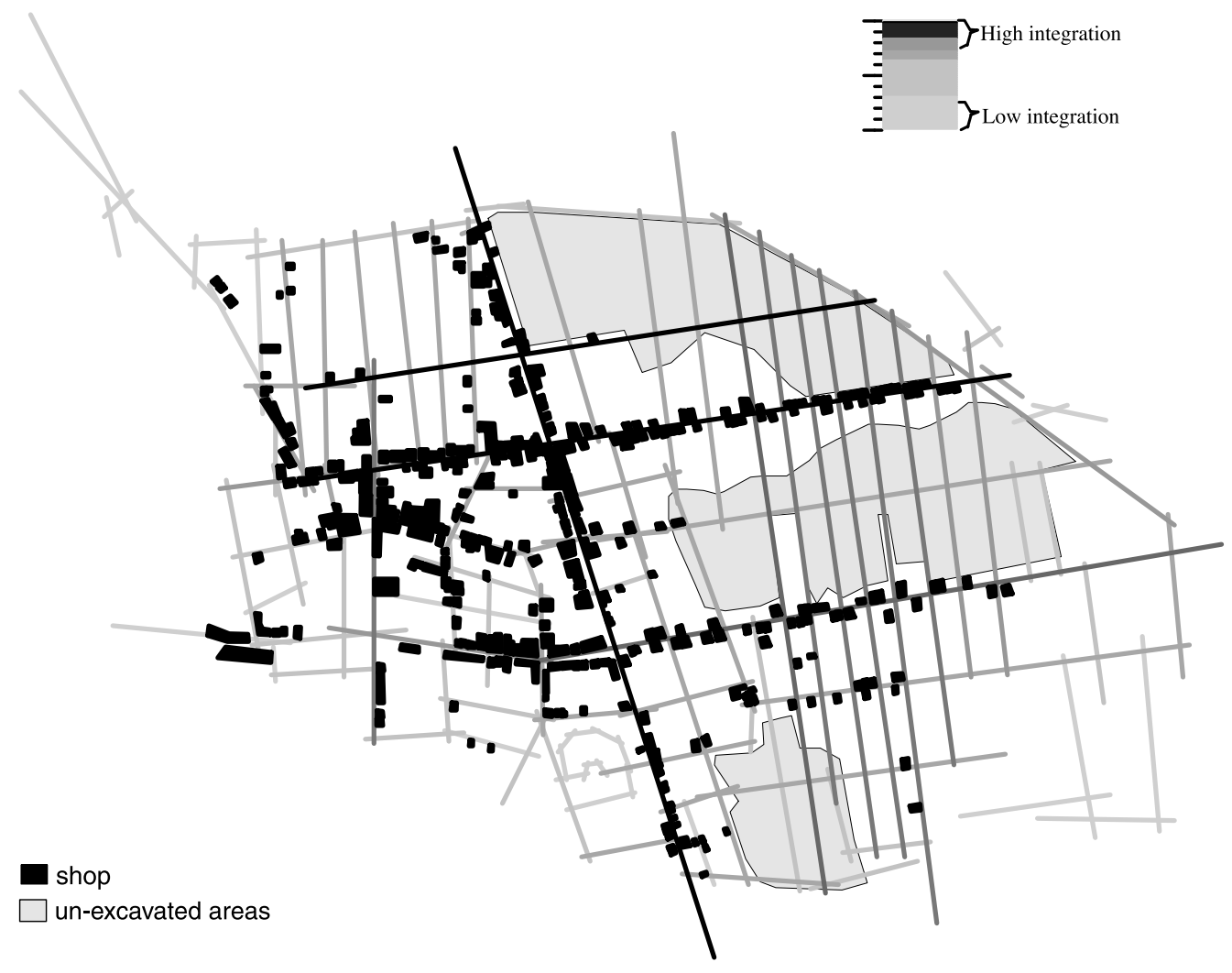

Figure 2 | Global integration analyses of Pompeii.

\section{The micro-scale tools}

Spatially, the focus in the macro-scale analysis is on how one street relates to all others in a city, while the focus in the micro-scale analysis is on the spatial relationship between spaces inside buildings and the streets. More precisely, it aims at defining the interrelationship of buildings or private spaces and adjacent street segments. The focus is on how dwellings relate to the street network, the way building entrances constitute streets, the degree of topological depth from private space to public space, and the intervisibility of doors and houses across streets. As Jane Jacobs and Jan Gehl argue, the existence of many entrances and windows facing a street is a way of ensuring urban liveliness (Jacobs 2000; Gehl I996). The challenge is to quantify these kinds of spatial relationships. What is important here is to measure various degrees of active urban frontages or the relationship between buildings and streets. Only then will it be possible to gain a genuine understanding of the spatial conditions for vital street life and urban safety. 


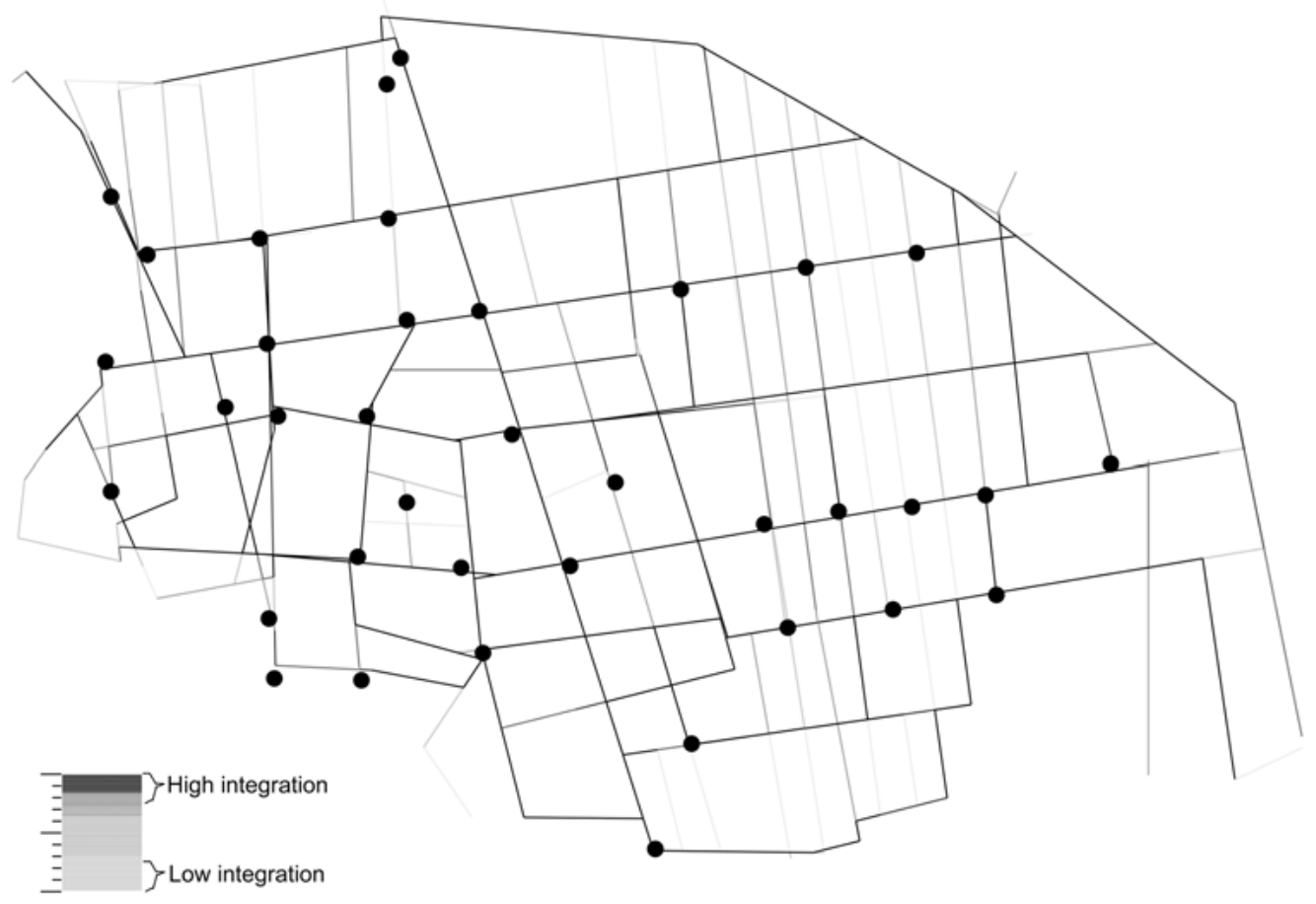

Figure 3 | Angular choice analyses with short metrical radiuses.

Moreover, in a research project on space and crime in Alkmaar and Gouda in the Netherlands, an opportunity was provided to register various spatial relationships between private and public spaces and compare the results with numerical social and economic data in a modern context (López and van Nes 2007). In total I,I68 street segments were observed and twenty-five different spatial features were registered for each segment. The results of the micro-spatial analysis were put in a Statistical Package for the Social Sciences (SPSS) database, together with various macro-scale variables derived from the space syntax analyses of the streets and street network, and the number and characteristics of residential burglaries and thefts from cars for each street segment. This research found that there was a correlation between a street network's spatial structure, the degree of intervisibility of entrances, and the incidence of crime; at the level of generalisation where integration values were high and the intervisibility of entrances was high, crime was low (López and van Nes 2007).

There are several ways of analysing spatial configurative relationships between building entrances and the street network. An easy way is to register the topological depth between private and public space. This involves counting the number of semi-private and semi-public spaces a person has to walk through to go from a private space to a public street. If an 
entrance is directly connected to a public street, there are no spaces between private and public space and depth is equivalent to zero. If there is a small front garden between the entrance and the public street, the depth value is one, since there is one space between the closed private space and the street. If the entrance is located on the side of the house and it has a front garden or is concealed by hedges or fences, the topological depth of the entrance has a value of two. In other words, the topological steps between the street and the private spaces inside buildings are being counted. In Pompeii the private space was found to be at the main entrance of the buildings.

Each side of a street segment is registered separately. There are many streets where entrances are directly connected to the street on the one side, while there is no entrance on the other side. If the side of a street segment has several depth values between private and public spaces, the average value is used. The diagram in figure 4 (top) illustrates various types of relationship between private and public spaces. The black dots represent the private spaces, while the white dots represent semi-private spaces. Casa di Octavius Quartio and Casa della Venere in Conchiglia are typical Pompeii houses, directly connected to the highly integrated street Via dell'Abbondanza. The main entrances of both houses are between two spaces, where probably shops were located in the past. Even though most of Pompeii's homes housed several families and the garden/courtyard probably functioned as a place for social interaction, they all had one main entrance directly connected to a public street.

A street's degree of constitutedness depends on various degrees of adjacency and permeability from buildings to public space. When a building is directly accessible to a street, it constitutes the street. Conversely, when all the buildings are adjacent to a street, but the entrances are not directly accessible, then the street is unconstituted (Hillier and Hanson I984, p. 94). A street segment is constituted when only one entrance is directly connected to the street. If the entrance is hidden behind high fences or hedges, has a large front garden, or is located on the side of the building, then the street is defined as unconstituted. The diagram in figure 4 illustrates the differences between constituted and unconstituted streets. The number and density of entrances are not considered in this case. The degree of constitutedness expresses the number of entrances connected to a street divided by the number of buildings located along that street.

As the results from the spatial analyses in Gouda and Alkmaar show, both micro- and macro-spatial variables are highly interdependent for describing an area's degree of liveliness (López and van Nes 2007). When a street segment is on a spatially integrated main route, or close to a main route, more buildings are directly connected to streets, and the entrances on each side of the street are intervisible to one another. Conversely, the further away a street segment is from a main route, the more building entrances are hidden away from streets and the degree of intervisibility between them is lower. These kinds of combination of macro- and micro-spatial conditions influence the degree of street life. The further away from main routes, the more silent street life tends to be. Most micro-spatial 


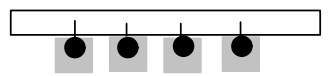

Entrances zero topological step between a street and private spaces

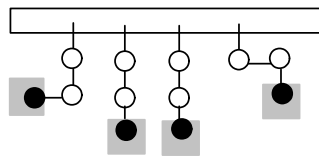

Entrances two topological steps between a street and private spaces

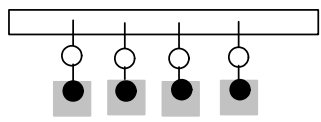

Entrances one topological steps between a street and private spaces

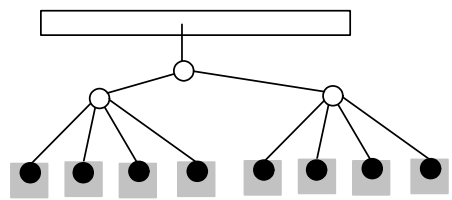

Entrances two topological steps between a street and private spaces

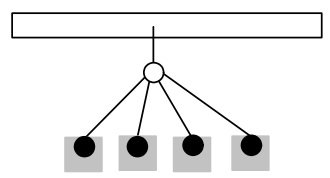

Entrances one topological steps between a street and private spaces

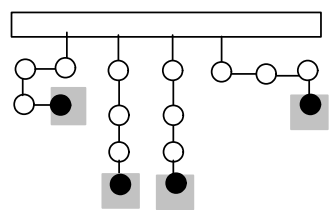

Entrances three topological steps between a street and private spaces

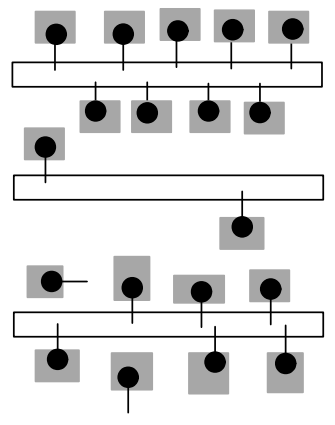

Examples on constituted streets
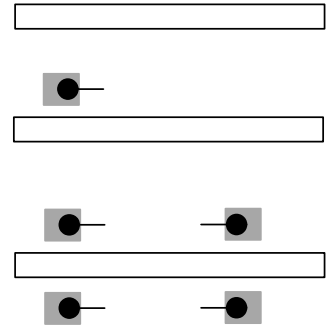

Examples on unconstituted streets

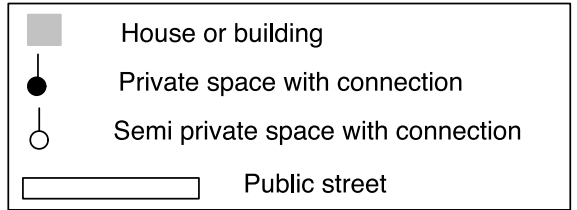

Figure 4 | Diagram showing the topological relationship between private and public space.

variables turn out to be related to the macro-scale variable local angular analyses. This variable identifies the main routes through cities and shows strong correlations with the microscale variables.

Through the Eschebachs' detailed mapping of buildings and their function, it is possible to carry out the micro-scale spatial analyses in Pompeii in the excavated areas of the city. One result is that all the entrances in the excavated areas are directly connected to the streets. Pompeii has in comparison with more modern European cities a well-connected and well-integrated street network. This might explain why there are almost no entrances hidden away from the public streets. When changing directions twice from Pompeii's main 
streets, a person is likely to end up in streets with very few or even no entrances. However, these entrances are still directly connected to the streets.

Figure 5 shows the difference between constituted and unconstituted streets in Pompeii. Unconstituted street segments are marked in grey, while the constituted ones are in black. All the shops are located along the constituted streets. The more entrances are connected to a street, the higher the probability that someone will come out from a private space into public space. However, the high density of entrances connected to a street does not always imply high inter-visibility. There is a distinction in the way entrances constitute streets and in the way they are intervisible to each other. The way entrances and windows are positioned to each

The density of entrances and degree of intervisibility was recorded separately. Thus, two buildings with two entrances facing each other indicate 100\% intervisibility of doors. Conversely, a street segment with a high density of entrances on only one side of the street segment is defined to be $\% \%$ intervisible. In Pompeii the percentages of the degree of intervisibility of entrances were grouped as 100\%, 50\% and ०\% intervisibility for each street segment. Figure 6 shows some diagrammatic principles on the relationship between intervisibility and density of entrances.

The distinctiveness of this feature can be clarified further with reference to figure 7 , which shows an example of a street with low intervisibility and low entrance density (left), and an example of a main street with high intervisibility and high density of entrances (right). The left example is a typical back street with only dwelling entrances (Via del Fuggiaschi), while the right example is Via dell'Abbondanza as a typical main shopping street in Pompeii.

Figure 8 shows the density (above) and degree of intervisibility (below) of entrances in Pompeii. The most integrated streets have the highest inter-visibility and density of entrances. By revealing the degree of constitutedness, it shows that Pompeii also had "silent" side and back streets with no entrances connected to these public spaces. Examples of silent unconstituted streets are Vicolo del Fuggiaschi and Via di Nocura, and examples of lively and constituted streets are Via dell'Abbondanza, Via di Stabia, Via Fortuna and Via di Nola.

A combination of various micro- and macro-spatial measurements makes it possible to capture data for relating the spatial to socio-economic circumstances and to provide an understanding of the spatial conditions for safe and vital urban areas. By the use of Depthmap software, various macro-scale spatial variables can be calculated and visualised. For example, a street with few connections to other streets (macro-scale analysis) can still be full of social activities, provided the street has a high density of entrances and when there is high visibility between public and private spaces (micro-scale analysis). The reverse can be seen in unconstituted streets with a low number of entrances and low inter-visibility, but where the connections to other streets are high. Independently of cultures and architectural styles, micro-spatial measurements make it possible to describe the spatial set-up of built environments at a local level. 


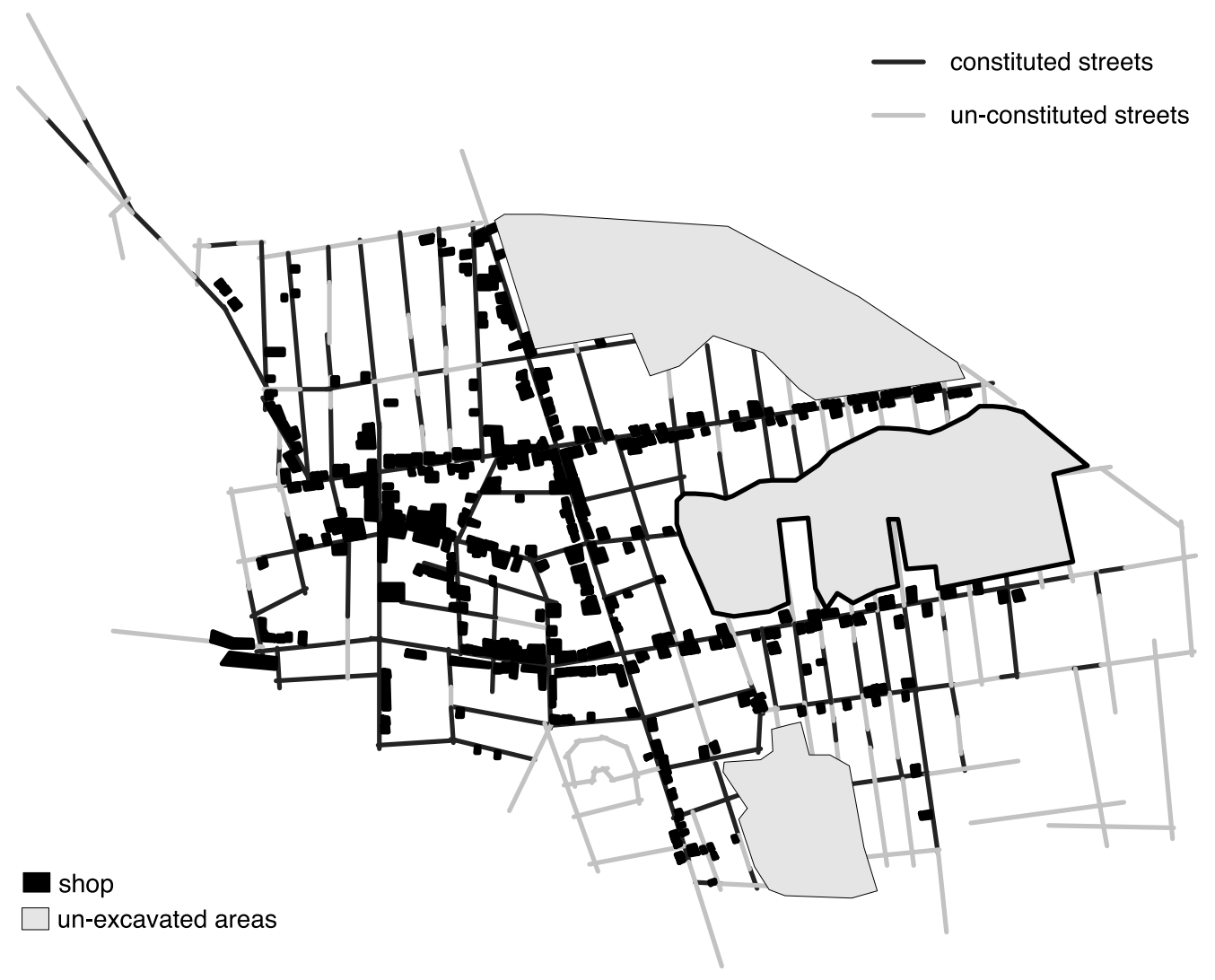

Figure 5 | Constituted and unconstituted streets in Pompeii.

Drawing on a study of a modern urban context, we find that the further away a street segment is from the main network of routes, the greater the topological depth between private and public space. Along the main routes through urban areas, most entrances are directly connected to the street. When direction is changed twice from the main routes, the average topological depth for entrances is 2 , while it is 3 in all street segments that are located more than six topological steps from the main routes. When comparing these data to those derived from Pompeii, we find numerous differences. Pompeii's orthogonal street grid is topologically shallow. By changing direction once from the main routes, which are defined as cardus and decumanus, most of the town's streets are covered. Therefore, all entrances in Pompeii are directly connected to streets. Furthermore, research has shown that in a modern urban context, the more segregated a street segment is, the more monofunctional the adjacent buildings tend to be. Topologically deeply located street segments usually only have a residential function, since offices, shops, and public buildings tend to locate along the main routes. The semi-private segments are among the topologically dee- 


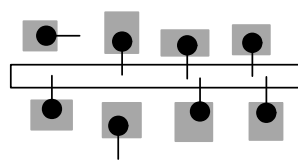

A high visible street $75 \%$ intervisibility

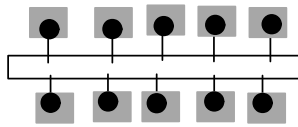

High density of entrances inter-visible to one another

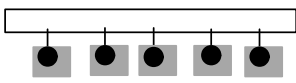

High density of entrances not visible to one another

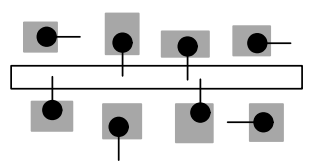

A medium visible street $50 \%$ intervisibility

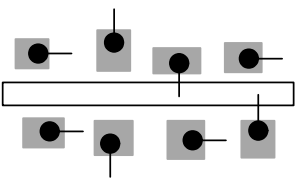

A low visible street $25 \%$ intervisibility

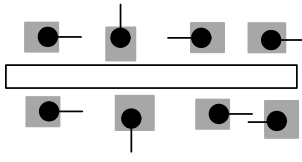

A non-visible street $0 \%$ intervisibility

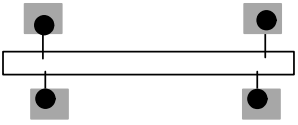

Intervisible streets with low density of entrances

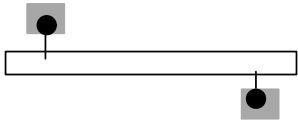

Low intervisibility and density of entrances
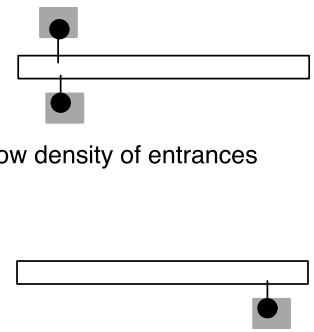

Low density of entrances, no inter-visibility

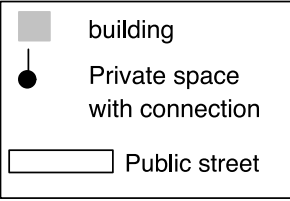

Figure 6 | The principles of intervisibility and density of entrances.
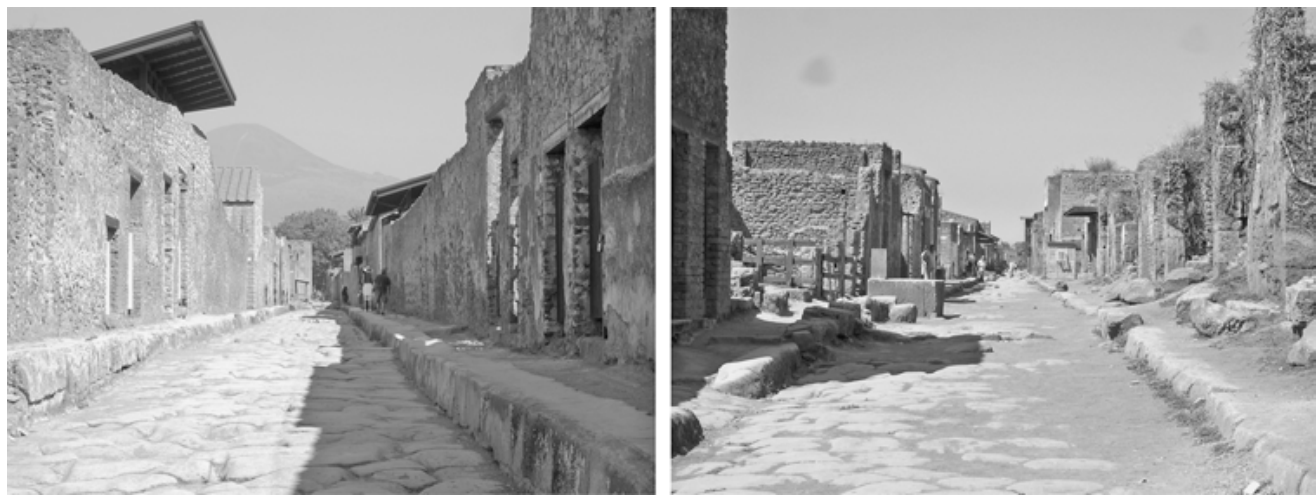

Figure 7 | Example of a side street with low intervisibility and density of entrances (left) and a main street with high intervisibility and density of entrances (right) in Pompeii.

pest and most segregated streets (López and van Nes 2007). In Pompeii entrances to dwellings tend to dominate the side streets, whereas there is a large mix of urban functions along the cardus and decumanus. Interestingly, the further a street segment is away from the main routes, the lower the values of spatial integration and constitutedness. The unconstituted back alleys tend to be the most segregated street segments.

As the study of street segments in a present urban context clearly shows, the microspatial conditions of the street segment are interrelated to the macro-spatial conditions of 


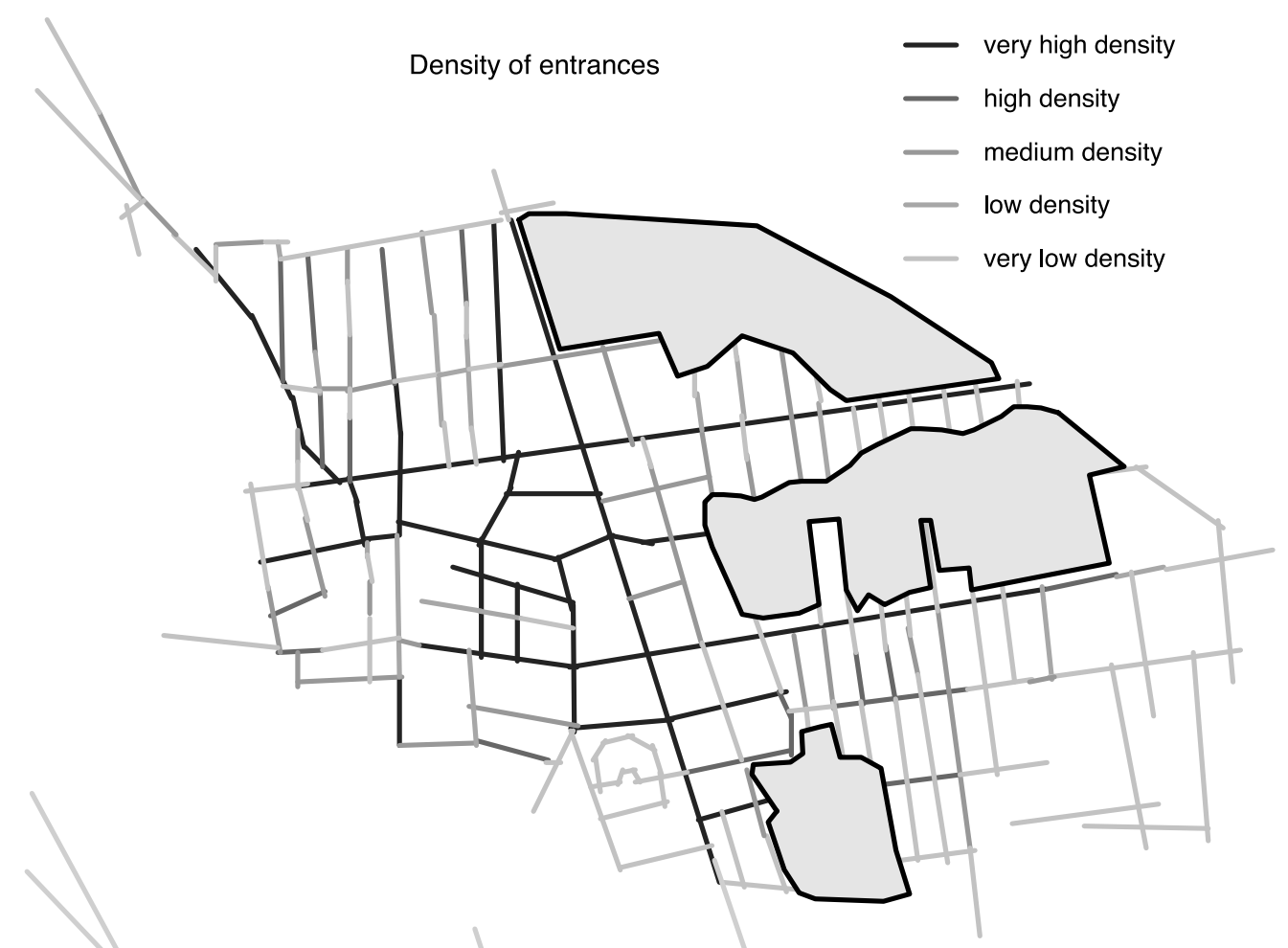

Degree of intervisibility between entrances

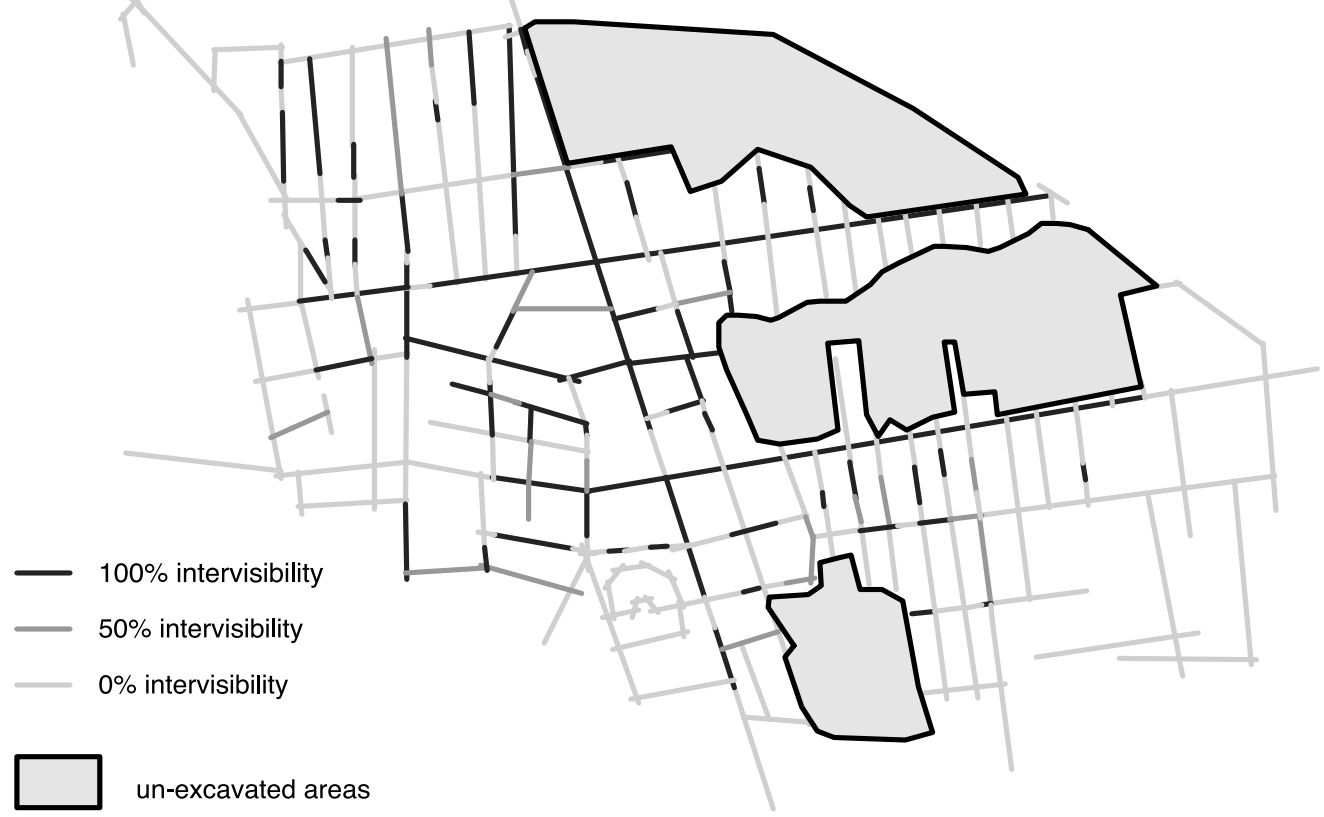

Figure $8 \mid$ The density and intervisibility of entrances in Pompeii. 
the cities' street network (López and van Nes 2007). The definition and operationalisation of the micro-scale conditions is, however, still in a preliminary phase and is an area that needs to be improved upon in the near future. Some concepts, at least, can usefully be introduced in order to describe and analyse the relationship between space and society on an urban micro-scale level for other excavated towns - even where the excavation is not of the scale of that conducted at Pompeii.

\section{Findings}

How do the spatial analyses of Pompeii contribute to an understanding of the social and economic life in past built environments? By putting all the archaeological data from the Eschebachs and the results from the various spatial analyses in different layers in auto-cad or GIS, it is possible to visualise the correlations between the various data. Moreover, by using SPSS, multi-variable analyses between macro- and micro-spatial parameters and socio-economic data from the past can be carried out. Given the archaeologists' detailed analyses of functions carried out within buildings, the following conclusions can be drawn about space and society in Pompeii.

Shops and bakeries locate in the most integrated streets, with a high number of connections to other streets in a short metrical distance. Moreover, the entrances along these streets are directly connected to the street, have a high density and high degree of intervisibility.

Religious buildings (such as temples) and political institutions locate themselves one topological step (or one direction change) away from the most integrated streets. They are seldom located along or at the end of the integrated main streets. The Temple of Fortuna Augusta is located at one of Pompeii's busiest junctions, which is where Via del Foro and Via del Fortuna cross. The temple's entrance is oriented towards Via del Foro, which is the second best integrated street. In some cases where temples are located along main streets, they can function as a negative generator for the location of shops. The entrances around these buildings have low density, but they still constitute the streets.

Brothels locate in constituted side streets metrically close to the integrated main streets. In contrast, workshops, taverns, and drinking places are located along the main streets and in side streets topologically close to the main streets. Conversely, the public baths, theatres, inns or hotels, sport, and leisure facilities are spread throughout the town's street network.

This pattern has implications for movement within Pompeii. The largest flow of pedestrians, equids or oxen-hauled vehicles was associated with the most integrated streets. Figure 9 shows the traces of 1500 people moving inside Pompeii's public spaces from the agent-based modelling in Depthmap. When we compare figure 9 with the spatial analyses, we see that the highest locally and globally integrated streets (from the macro-scale analy- 


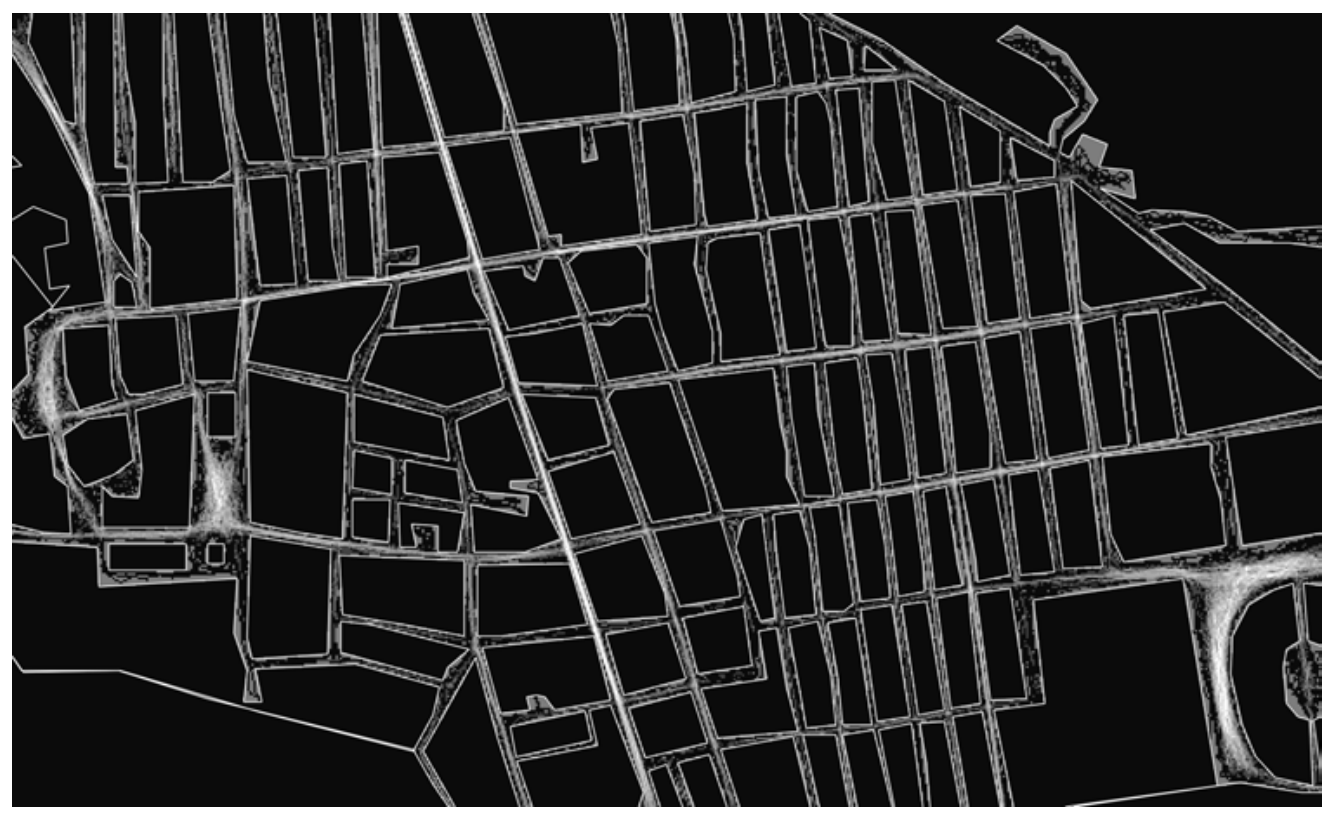

Figure 9 | Agent-based modelling of Pompeii's public spaces.

sis) combined with the highest density of entrances (from the micro-scale analysis) are the most frequented urban spaces.

In general, it can be said that the way a society organises its functions spatially and the way its spatial structure affects human behaviour, in terms of the location pattern of its activities, has not changed much in two thousand years. The same tendencies in space and human behaviour can be seen in urban centres in modern cities.

Micro- and macro-spatial relationships play a crucial role in the socio-economic life of human beings in built environments. All these activities depend on how the spatial configuration is on the "plinth" or built-up sides of the street. The street plinth is where the building meets the street. It is at the street plinth that the micro-scale and macro-scale analyses, which determine the degree of liveliness in streets, are interconnected. The microspatial structure of the urban street plinth affects the direct interface of public and private life of a built environment's inhabitants and visitors in an informal way. It has always been like this in built environments. Even though Pompeii's street network was planned according to the ancient ideal city type with its strict orthogonal street grid containing two main streets intersecting in the middle, the location process of buildings along streets occurred organically. The most integrated and crowded streets were the most attractive for locating the entrance of an adjacent building. Hence a street network's macro-spatial structure affects the degree of attractiveness for economic and social activities. In Pompeii, most entrances are packed together on the shortest sides of their insulae due to high spatial inte- 
gration values on the streets on that side. These micro- and macro-spatial conditions made it optimal for the exchange of goods, shopping activities, social interaction, and the vitality of street life in Pompeii's main streets.

Since previous research, analyses, and functional designation of buildings in Pompeii offer a comprehensive set of data of archaeological artefacts, what are then the challenges for the future application of spatial configurative methods on other excavated sites? In the first instance, a reconstruction of a town's street pattern must be available. It is the necessary basis for the macro-scale spatial analysis. This makes it possible to indicate the spatial potential for the degree of street vitality and street life. Secondly, precise mapping of walls and entrances provides the basis for micro-scale spatial analysis. In cases where it is impossible to ascertain a site's street network, micro-scale analysis can to some extent give the spatial indications of how lively or quiet a street probably was in the past. Herculaneum represents a town of this kind, where large parts are still un-excavated. Its twelve excavated street segments show a large variation in inter-visibility, permeability, and adjacency between private and public space on the street plinth level. It is at least a beginning for indicating various degrees of street life in past built environments.

The application of space syntax and the micro-scale tools contributes to understanding how ancient cities functioned and what the relationship is between spatial layout and socioeconomic activities. Spatial analysis of the street network gives indications of possible functions in adjacent buildings, where identifiable artefacts are lacking on archaeological sites. Finally the statistical data from the micro- and macro-scale spatial analysis and agent-based modelling can indicate the degree of vitality in shopping streets and where the largest flow of human movement took place in the past.

\section{Bibliographical references}

Crane, M. (2009)

“The Medieval Urban 'Movement Economy' Using Space Syntax in the Study of Medieval Towns as Exemplified by the Town of 's-Hertogenbosch, the Netherlands", in: D. Koch, L. Marcus, and J. Steen (eds.), Proceedings Space Syntax. 7th International Symposium, Stockholm. http://www.sss7.org/Proceedings/o7\%20Urban\%20Structures\%20and\%20Spatial \%20Distribution/oI9_Craane.pdf (18 July 2013).

DeLaine, J. (2004)

"Designing for a Market: Medianum Apartments at Ostia", in: Journal of Roman Archaeology I7, pp. I46-I76.

Eschebach, H. (1970)

Die städtebauliche Entwicklung des antiken Pompeji. Die Baugeschichte der Stabianer Thermen, Heidelberg.

Eschebach, H. (1978)

Pompeji, Leipzig. 
Eschebach, L. (1993)

Gebäudeverzeichnis und Stadtplan der antiken Stadt Pompeji, Köln, Weimar, Vienna.

Fridell Anter, K., and Weilguni, M. (2003)

"Public Space in Roman Pompeii", in: G. Malm (ed.), Towards an Archaeology of Buildings: Contexts and Concepts, BAR International Series II86, Oxford, pp. 3I-39.

Gehl, J. (1996)

The Life between Buildings: Using Public Space, Copenhagen.

Hillier, B. (1999)

Space as Paradigm for Describing Emergent Structure in Strongly Relational Systems, Lecture notes, Bartlett School of Architecture, UCL, London.

Hillier, B., Penn, A., Banister, D., and Xu, J. (1998)

"Configurational Modelling of Urban Movement Networks", in: Environment and Planning B: Planning and Design 25, pp. 25-84.

Hillier, B. and Hanson, J. (1984)

The Social Logic of Space, Cambridge.

Jacobs, J. (2000)

The Death and Life of Great American Cities, London.

Kaiser, A. (2000)

"The Urban Dialogue: An Analysis of the Use of Space in the Roman City of Empúries, Spain", in: British Archaeological Reports International Series 90I, Oxford, pp. I-I32.

Laurence, R. (1996)

Roman Pompeii: Space and Society, New York.

López, M., and van Nes, A. (2007)

"Space and Crime in Dutch Built Environments. Macro and Micro Spatial Conditions for Residential Burglaries and Thefts from Cars", in: A. S. Kubat (ed.), Proceedings Space Syntax. 6th International Symposium, Technological University Istanbul, Istanbul http://www.space syntaxistanbul.itu.edu.tr/papers\%5Clongpapers\%5Co26\%20-\%20Lopez\%20vanNes.pdf (I8 July 20I3).

Marcus, L. (2000)

Architectural Knowledge and Urban Form. The Functional Performance of Architectural Urbanity, Stockholm (PhD thesis).

van Nes, A., and López, M. (2010)

"Macro and Micro Scale Spatial Variables and the Distribution of Residential Burglaries and Theft from Cars: An Investigation of Space and Crime in the Dutch Cities of Alkmaar and Gouda", in: Journal of Space Syntax, Vol. 2, pp. 296-3I4.

van Nes, A. (2005)

"Typology of Shopping Areas in Amsterdam", in: A. van Nes (ed.), Proceedings Space Syntax. 5th International Symposium, Amsterdam. 
van Nes, A. (2002)

Road Building and Urban Change. The Effect of Ring Roads on the Dispersal of Shop and Retail in Western European Towns and Cities, Ås (PhD thesis, Agricultural University of Norway).

Newsome, D. J. (2009)

Traffic, Space and Legal Change around the Casa del Marinaio at Pompeii (VII 15.1-2), in: Babesch 84, pp. I2I-I42.

Poehler, E. E. (2006)

"The Circulation of Traffic in Pompeii's Regio VI", in: Journal of Roman Archaeology I9, pp. 53-74.

Turner, A. (2004)

Depthmap 4 - A Researcher's Handbook, London.

\section{Stöger, H. (2009)}

"Clubs and Lounges at Roman Ostia. The Spatial Organisation of a Boomtown Phenomenon (Space Syntax Applied to the Study of Second Century AD 'Guild Buildings' at a Roman Port Town)", in: D. Koch, L. Marcus, and J. Steen (eds.), Proceedings Space Syntax. 7th International Symposium at KTH, Stockholm http://sss7.org/Proceedings/03\%20Spatial\%20Analysis \%20and\%20Architectural\%20Theory/I08_Stoeger.pdf (I8 July 2013).

Zanker, P. (1998)

Pompeii. Public and Private Life, Harvard. 
